\title{
Primary Health Care Development: Where is Nepal after 30 years of Alma Ata Declaration?
}

\author{
Karkee $\mathrm{R}^{1}$ Jha $\mathrm{N}^{1}$ \\ 'School of Public Health and Community Medicine, BPKIHS, Dharan, Nepal.
}

\section{ABSTRACT}

The year 2008 has witnessed the global conversation to return to tenets of Alma-Ata and to review its 30 years of journey. We reviewed Nepal's journey on Primary Health Care development: policy formulation, structure development, progress and constraints. Though Nepal has institutionalised the PHC approach in health policy, strategy and health care delivery system, this has not been effectively translated into actions, and the results are mixed. Nepal has gained impressive achievements in selective primary health care markers: $45.43 \%$ maternal mortality and $62.34 \%$ child mortality reduction during 1990-2005. But gain in comprehensive health care markers is not impressive: $18.7 \%$ Skilled Birth Attendant (4\% in poorest quintile and 45\% in richest quintile), 39\% having access to improved sanitation and $55.7 \%$ of females are literate as compared to males. Socio-political environment until recently was not favourable for comprehensive primary health care, allowing limited health sector decentralisation and community empowerment. Health activities were focussed more on selective health care strategy in the form of disease control, immunisation, vitamin A supplementation, oral rehydration solution use and contraceptive use. Nepal's rural hilly geography posed great challenge on logistic supply, communication and retention of health workers rendering public health centres of low quality with negative perceptions of consumers. Nepal is on the pathway to build equitable comprehensive primary health care.

Key Words: constraints, development, Nepal, primary health Care, progress

\footnotetext{
Correspondence:

Mr. Rajendra Karkee

School of Public Health and Community Medicine

BP Koirala Institute of Health Sciences, Dharan, Nepal.

Email: rkarkee@yahoo.com

Phone: 9842064635
} 


\section{INTRODUCTION}

The year 2008 has witnessed the plethora of events to analyse three decades of PHC activities. ${ }^{1,2}$ During the 30 years of primary health care $(\mathrm{PHC})$ journey, the movement has seen many up and downs, success and failure and criticisms and favours. ${ }^{3,4}$ There is now worldwide voice to return to tenets of Alma Ata as a solution to current crisis in health: increasing demands, rising costs, weak health systems and increasing disparity in health across globe and within country among rural/urban, male/female, and rich/poor. ${ }^{5,6}$ Primary health care strategy is once again reaffirmed as the best methods to achieve equitable, affordable and sustainable health care and promising way to achieve millennium development goals locally, nationally and globally. ${ }^{6,7}$

This renewed interest in comprehensive $\mathrm{PHC}$ has obviously recognised the importance of contents of Alma Ata declaration: the basic eight elements of essential health care, which can result a quality of life by fostering social development of any community and nation. Its principle of equity, community participation, intersectoral coordination, and appropriate technology has proved time tested ever relevant tolls for the world to attain health for all. ${ }^{6}$ So, it is time for each nation and society, especially those that have still poor health, to review their 30 years journey towards health for all, to analyse what worked and what did not worked and how they move forward..$^{3,7}$ In this context, we reviewed Nepal's journey on PHC development: policy formulation, structure development, progress and constraints with recommendations for future.

Health Infrastructure Development in Nepal About half a century ago, Nepal was rampant with communicable diseases and lack of basic sanitation. Health care was restricted to a few urban hospitals and a few rural dispensaries. Department of health services was established in 1933 (later became ministry of health in 1956) and started to control communicable diseases by establishing major vertical programmes of malaria, leprosy, tuberculosis, and smallpox. The smallpox eradication programme later became Expanded Programme in Immunisation (EPI) in 1977. During 1970s, integration of vertical projects took the shape of district health offices. The ministry underwent a major reorganisation in 1987 and again in 1991 (Panel 1). ${ }^{8}$ Currently, the Ministry has a central section and three departmentsdepartment of drug administration, department of ayurveda and department of health services. The central section with its four divisions is responsible for administration, monitoring and evaluation, and policy making, planning, financing and international co-operation.

Department of health services is responsible for provision of all curative, preventive and promotive health services. The 1991 health policy aimed to establish a good district health system: a district health office including district hospital in each district, a primary health care centre (PHCC) in each electoral constituency, a health post (HP) in five Village Development Committees (VDCs), subhealth post (SHP) in each VDC, and PHC outreach clinics, EPI outreach, Female Community Health Volunteers (FCHVs) and Traditional Birth Attendants (TBAs) at ward level. ${ }^{9}$ This sanction of health units has been nearly fulfilled. Out of 75 districts, 60 have district health offices, 65 have district hospitals, and 15 have district public health offices. There are 209 PHCC 10.8 PHCC per 100000 population), 677 HPs, 3126 SHPs, 15257 TBAs and 48445 FCHVs.10 This has resulted in twelve fold growth in health facilities during 1992-1996. Sixty two percent of people have access to HP/SHP within half an hour of travel on foot. ${ }^{11}$

In principle, community mobilisation and community and family health care such as promotion of safe motherhood, child health, family planning are performed by FCHV and SHP; outpatient health care by HP and PHCC; basic inpatient health care by district hospital; and referral services by zonal, regional and central hospitals. Category of health care workers in Nepal include Medical Officer/Doctor, Staff Nurse (SN), Health Assistant (HA), Auxiliary Health Worker (AHW), Village Health Worker (VHW), Maternal and Child Health Worker (MCHW); while FCHV and TBA are health care volunteers. The overall ratio of health care workers (excluding volunteers) to population in Nepal is more than that of Thailand and Sri-Lanka. ${ }^{12}$ However, the ratio of doctors, nurses and health volunteers are more in Thailand and Sri-Lanka than in Nepal.

\section{Health Policy Inclination towards PHC}

Having signed the Alma Ata declaration of 1978, the policy and plan of Government of Nepal (GoN) has shown continued adherence to the PHC approaches. Nepal's first long term health plan aimed at structuring and functioning of the health services towards the emergence of district health services. Emphasis was put on regulating population growth through promotion of family planning and expansion of maternal and child health services and on intersectorial co-ordination with food supply and safedrinking water. ${ }^{13}$

Following the people's Movement of 1990 and restoration of multiparty democracy, a radical National Health Policy was brought out in 1991 whose primary objective was to extend the PHC system to the rural population through health infrastructure development (one sub-health post in every village development committee), community participation, multi-sectoral co-ordination, mobilising local resources and decentralised planning and management 
to district level. ${ }^{9}$ Subsequent plans have been built on that policy. Second Long Term Health Plan (1997-2017) stressed equitable access and quality service to all; especially improving the health status of those whose health needs often are not met: the most vulnerable groups, women and children, the rural population, the poor, the underprivileged and the marginalised. ${ }^{14}$ It aimed to provide Essential Health Care Package (EHCS) through district health system to the grass root level. EHCS packages includes a total of 20 interventions in the area of family planning, safe motherhood and neonatal, child health, communicable disease, out-patient care. The key focus of the Nepal Health Sector-Implementation Plan is to increase coverage and quality of the EHCS. ${ }^{15}$ The 10 th plan and poverty reduction strategy paper (PRSP) have advocated expansion and upgrading of the $\mathrm{PHC}$ centres and districts hospitals to develop and mobilise the healthy human resource for poverty reduction. ${ }^{16}$ The latest three year interim plan (2007-10) includes free basic health services (registration fee, available health services and essential drugs) to all citizens in government HPs/SHPs and to poor, destitute, disabled, senior citizens and FCHVs in government district hospital and PHCCs. In short, Nepal has institutionalised the PHC approach in health policy, strategy and health care delivery system, that is comparable to the high performance countries in the region such as Sri-Lanka or Thailand. ${ }^{17-19}$ However Sri-Lanka or Thailand had PHC structure and policy as early as the time of Alma-Ata Declaration.

\section{Mixed Progress}

In an international analysis of 80 low and middle income countries that have a gross national income (GNI) per person of less than US\$ 5000 in 2006, Nepal comes on overachieving countries based on life expectancy in relation to GNI per person and HIV/AIDS prevalence. ${ }^{20}$ In the same analysis, Nepal comes on 9th position in the top 30 countries out of those 80 countries in average yearly rate of reduction in mortality among children aged less than five years from 1990 to 2005 . This is something to be proud of in the provision of primary health care in Nepal, especially in child and maternal mortality reduction, and immunisation coverage, though maternal mortality ratio (MMR), neonatal mortality rate and contraceptive prevalence rate in Nepal are still high. ${ }^{21}$ On the other hand, indicators of comprehensive PHC development such as Skilled Birth Attendant (SBA), intersectoral care such as access to clean water and improved sanitation and gender inequality in literacy, and equity status such as urban/rural disparity and SBA across income groups are not promising, lagging far behind to successful countries like Thailand and Sri-Lanka (Table 1). Women in the poorest quintile receive antenatal care three times less and professional attendance in deliveries 11 times less than women in the richest quintile. The percentage of underweight children is five times higher among the poorest quintile compared to the richest. ${ }^{22}$ Percentage of people using improved drinking sources has substantially increased but sanitation and environmental measures are still poor.

Panel 1. Time line of health structure and policy development in Nepal.

- 1933- Establishment of Dept of Health services (DoHS)

- 1950s- 1 st five year plan and Malaria Eradication Program

- 1960s-Family Planning and Maternal and Child Health, Leprosy, Tuberculosis, Small Pox, Central Health Laboratory

- 1970s - Integration of vertical projects started into one umbrella as District Health Office

- Nepal's first Long Term Health Plan (1975-90) - to ensure consistent and proper functioning of the health services

- 1980s-

- $\quad$ 7h plan period (1985-90) - Organisational changeDoHS dissolved and 5 Regional Health Directorates and 75 district public health offices established (Decentralisation Act, 1982)

- Department of Ayurved and Drug Administration established

- 1990s (Movement of 1990)

- National Health Policy-1991

- Health system reorganisation

- Second long term health plan (SLTHP, 1997-2017)

- 2000s (Health Sector Reform)

Strategic Analysis to operationalise SLTHP, 2000 Operational issues and prioritisation of resources, 2000

- Medium Term Strategic Plan 2001

Poverty Reduction Strategy Paper (PRSP, 2002-7) 10th plan (2003-8)

Nepal Health Sector Reform Strategy, 2003

- Nepal Health Sector Strategy Implementation Plan, 2003

- Three year Interim Plan (2007-10)

\section{JNMA $\mid$ VIL 49 Na. 2 ISSUE 178 APR-JUN, 2010}


Table 1. Comparison of selected indicators among Nepal, Sri-Lanka and Thailand during 1980-2005. Data are derived rom WHO/SEARO country health system profile and Human Development Report, 2007-8.

\begin{tabular}{|c|c|c|c|c|c|c|c|c|c|}
\hline & \multicolumn{3}{|c|}{ Nepal } & \multicolumn{3}{|c|}{ Sri-Lanka } & \multicolumn{3}{|c|}{ Thailand } \\
\hline & 1980 & 1990 & 2005 & 1980 & 1990 & 2005 & 1980 & 1990 & 2005 \\
\hline Maternal Mortality Ratio & - & 515 & 281 & - & 92 & 47 & - & 36 & 14 \\
\hline Mortality reduction in 1990-2005 & - & \multicolumn{2}{|c|}{$45.43 \%$} & \multicolumn{3}{|c|}{$48.91 \%$} & - & \multicolumn{2}{|c|}{$61.11 \%$} \\
\hline Mortality rate for children $<5$ years & - & 162 & 61 & - & 22 & 16 & - & 58 & 28 \\
\hline Mortality reduction in 1990-2005 & - & \multicolumn{2}{|c|}{$62.34 \%$} & - & \multicolumn{2}{|c|}{$27.27 \%$} & - & \multicolumn{2}{|c|}{$51.72 \%$} \\
\hline \multicolumn{10}{|l|}{ Immunisation of 1-year-old children } \\
\hline with measles & $2 \%$ & $42 \%$ & $85 \%$ & - & $80 \%$ & $99 \%$ & - & $78 \%$ & $84 \%$ \\
\hline Contraceptive prevalence & - & $26 \%$ & $48 \%$ & - & - & $70 \%$ & $53 \%$ & $70 \%$ & $74 \%$ \\
\hline \multicolumn{10}{|l|}{ Skilled Birth Attendant } \\
\hline (SBA) & - & $3.1 \%$ & $18.7 \%$ & - & - & $97 \%$ & $36 \%$ & $88 \%$ & $98 \%$ \\
\hline SBA in poorest quintile (2005) & $4 \%$ & & & - & - & - & $93 \%$ & & \\
\hline SBA in richest quintile (2005) & $45 \%$ & & & - & - & - & $100 \%$ & & \\
\hline Underweight Children & $50 \%$ & $57 \%$ & $39 \%$ & $38 \%$ & $38 \%$ & $29 \%$ & $37 \%$ & $19 \%$ & $9 \%$ \\
\hline \multicolumn{10}{|l|}{ Total population using improved } \\
\hline \multicolumn{10}{|l|}{ Total population using } \\
\hline improved sanitation & - & $6 \%$ & $39 \%$ & - & $73 \%$ & $80 \%$ & - & $74 \%$ & $98 \%$ \\
\hline Adult literacy (2005) & $49 \%$ & & & $90 \%$ & & & $96 \%$ & & \\
\hline \multicolumn{10}{|l|}{ Adult literacy for female as \% } \\
\hline of male (2005) & $55.7 \%$ & & & $97 \%$ & & & $95.4 \%$ & & \\
\hline Pop living on $<\$ 1$ a day (2005) & $24.1 \%$ & & & $23 \%$ & & & $3.5 \%$ & & \\
\hline \multicolumn{10}{|l|}{ Government expenditure on health } \\
\hline out of total health expenditure (2005) & $28 \%$ & & & $45 \%$ & & & $57.1 \%$ & & \\
\hline
\end{tabular}

Such unequal performance on comprehensive versus selective primary health care indicates that Nepal is still on the pathway to build comprehensive and equitable primary health care system. One of the reasons behind this is our heavy inclination towards selective primary health care and biomedical model of health care, often favoured and assisted by donors and non-governmental organisations (NGOs), rather than comprehensive and social model of health care. This is also evident by our past decades activities heavily concentrated on vertical programmes, which still continues as EHCS packages, in the form of disease control, immunisation, vitamin $A$ supplementation, oral rehydration solution use and contraceptive use. Most of these interventions have been based on and still confined to primary health care workers or volunteers such as $\mathrm{MCHW}$ or $\mathrm{FCHV}$, by means of short-term community mobilisation, rather than facilitybased services. Though, such health care workers are immense help to provide promotive and preventive services, ${ }^{23}$ curative and life-saving services can not be expected from them. MCHW and ANM, responsible to provide obstetric first aid at the village level in Nepal, are not successfully functioning as SBA. ${ }^{24}$ An effective referral system that can manage curative or complex care (such as obstetric services) has poorly developed. ${ }^{25}$ Constraints on the Pathway to Comprehensive PHC

The central tenets of Alma-Ata Declaration mainly community participation and empowerment, decentralisation, intersectoral collaboration could not be effectively implemented over the past three decades. There are varieties of reasons. Firstly, the primary health care development is greatly affected by the prevailing socio-political environment. The one party Panchayat regime from 1960 to 1990 was heavily centralised leading to limited community empowerment and decentralisation. Besides, the heavy gender disparity and rooted hierarchical social caste system prevented lower caste and women from equal participation socially, economically and politically, producing unequal societies. ${ }^{26}$ Even after restoration of multiparty system in 1991, the political instability and persistent disparity took the country over the decade of internal violent conflict of which the population health impact is immense. ${ }^{27}$ The work culture was not often service and quality oriented. In spite of stated objectives that the health offices and hospitals

\section{JNMA VLL 49 Na. 2 ISSUE 178 APR-JUN, 2010}


exists to provide health services with task-oriented staff it could be observed in practice that the underlying attitudes, assumptions and decisions are often different: most posts do not have job descriptions; staff are recruited on the basis of factors other than the skills or knowledge required; trainings and supervisions are seen commonly as means of earning extra allowances; and service quality is not seen as priority. ${ }^{28}$ Social services, social justice, governance, economics, education, nutrition have not progressed for significant health development in Nepal over the past three decades. Presently, Human Development Index for Nepal is 0.534 (142nd out of 177 countries); Human poverty index for developing countries (HPI-1) is $38.1 \%$ (84th position out of 108 countries); $24.1 \%$ of population earns less than a dollar per day; $51.4 \%$ of adult are illiterate (14th among 164 developing countries); and $48 \%$ of children under five years are underweight (highest in the world). ${ }^{22}$

Secondly, the health sector decentralisation and community empowerment, gender equity and intersectoral collaboration were much talked of than done in the field during most of the past decades. Health system decentralisation was affected by the organisational structure, tension in the system, resource regeneration, allocation, planning and management, participation and accountability. ${ }^{29}$ There is still unclear definition of the health and health care responsibilities of the centre, region and the local bodies, often overlapping the role and responsibilities. ${ }^{30}$ The role of regional health directorate is not clear. The final local governance act was implemented only in 1999, which intends to hand over local health facilities to local bodies in phase-wise manner. Co-ordination mechanism among district health offices, VDCs and municipalities to work together, especially to involve community actively is not evident. Community participation mainly relied on community health volunteers, who were not often supported by health system. Mass mobilisation did not appear as sustained and at scale. The deep rooted social preference of son and property authority to male has hindered in the provision of gender equity laws until recently. ${ }^{31}$

Thirdly, hilly and rural geography of Nepal, where more than $80 \%$ populations are residing, has posed great challenge to maintain quality of health care in lower health units, especially retaining health workers in rural health units and providing essential logistics over the past decades. Tertiary level health education institutes were no more interested in producing mid and low level health workers. Private sectors were more involved in educational training of mid and low level health workers as well as doctors and nurses. Medical education became expensive out of reach of common and rural people. This has not favoured to produce socially accountable health workers. Many health units and district hospitals, especially in remote areas, were devoid of health workers, essential drugs and physical facilities. ${ }^{32}$ They remained in structure but could exhibit little functionality. As a result, consumers had negative perceptions, mainly due to lack of drugs and health workers, regarding such public health posts and centres, ${ }^{33-34}$ which remained bypassed to tertiary centres or private centres: only $44 \%$ of people consult government health institutions (17\% SHP, 11\% HP, 16\% PHCC/Hospital) for their acute illnesses. ${ }^{11}$ In spite of physical accessibility, a large number of the female community is facing difficulties in accessing the health care services even at the nearest health care system. ${ }^{21}$ Besides private hospitals and private nursing homes, the country had al least 10000 private pharmacies, ${ }^{18}$ often conducted by low level health workers (HA or AHW), who also work in government health services. People were easily attracted to these pharmacies apparently due to better counselling, quick service and availability of medicines.

\section{Relevancy of Alma-Ata and Revitalising}

Alma Ata declaration for Nepal is even more relevant now than it was 30 years ago. ${ }^{35}$ Donor Countries and developmental partners are now more convinced to comprehensive participatory approach, poverty reduction, sustainable health system development and sector-wide approaches. We have now more resources in terms of health workers and technology. The country's sociopolitical environment is now conductive for decentralisation, community empowerment, and equity. The health is already a basic human right in constitution. Could we trap these ample opportunities for the second generation of primary health care revolution in Nepal? Could we complete building a comprehensive, equitable and universal primary health care system in a coming decade?

For our second generation of primary health care revolution, we need specific implementation planning process, leading to district action, for we already have policy and guidelines. We did need to look upon what worked, what did not worked and why and what must be done. Here, we want to highlight on following points that we believe important and relevant for Nepal's primary health care reform:

\section{PHCC as Gate keeper}

The PHCC centre is the lowest level of health facility having medical doctor with curative service. These centres should be supplied with "family/general practioner doctors", linked with district or regional hospitals up and with HP/SHP below and should be turned to effective gate keepers for general people for basic curative services. This will increase utilisation and trust on PHCC of consumers, reducing their opportunity costs.

\section{JNMA $\mid$ VaL 49 Na. 2 ISSUE 178 APR-JUN, 2010}




\section{Creating and Retaining Health Workers}

For the vast level of rural areas and rural communities, low and mid-level of health workers such as HA, AHW, ANM are the only hope and likely to sustain especially, when they are from the same areas and society. 36 Choice of students from rural areas, reservation of seats for poor communities and local placement are necessary. State should be involved on their training, monitoring, retraining and promotion. State should take more responsibility for medical graduates training, more funding is necessary for general lay people to study medical science and mandatory three years rural posting after graduation should be applied.

\section{Community Empowerment and Rights-Based Approach}

Health can not be improved without people's active participation, which is not easy to perform. Community participation and empowerment are related- one leads to another. Low and mid-level health workers, especially health volunteers should be involved and supported to act as efficient facilitators for health education and other participatory process where people form groups (such as women's groups), gather resources and plan, work and evaluate together, as an active agents of change. ${ }^{37}$ ${ }^{41}$ This process can also be facilitated by private organisation and civil society leaders. When people are empowered, it is very easy to process rights based approach whereby people can raise their voice making authority and responsible persons more accountable.

\section{Intersectoral Effort and Integrated Approach}

Intersectoral action is most difficult to bring about but most essential for health improvement. ${ }^{42}$ Health care workers may overlook the role of other sectors such as agriculture, education, water and sanitation and those sectors may consider that health is not their priority. So, a new appealing concept to all should be sought out such as "quality of life for all" rather than "health for all", whereby joint ownership and shared responsibilities among different sectors can be generated as in Thailand. ${ }^{13}$ District Development Committees, Village Development Committees and Municipalities are the appropriate platforms for all sectors and all level of people to join hands to conduct such concept, effectively co-ordinated by health officers. This will greatly help community mobilisation and synergistic effects on health improvement. On the other hand, within health sector, an integrated or diagonal approach should be adopted to move both vertical and comprehensive care together. Platforms for selective packages of care for maternal, newborn and child health can be utilised to include mental health, overall child development and maternal health (life-cycle approach), chronic disorders, diabetes and other long term outcomes towards a continuum of care approach.

\section{SUMMARY}

Nepal has institutionalised the PHC approach in health policy, strategy and health care delivery system. However, this has not been effectively translated into actions, and the results are mixed. Nepal has gained impressive achievements in selective primary health care markers while gain in comprehensive health care markers is not impressive. Health activities in the past were focussed more on selective health care strategy in the form of disease control, immunisation, vitamin A supplementation, oral rehydration solution use and contraceptive use. Nepal is on the pathway to build equitable comprehensive primary health care and its national health policy, strategy and health care delivery system needs revitalisation in terms of physiological boost.

\section{REFERENCES}

1. Wibulpolprasert S, Tangcharoensathien V, Kanchanachitra C. Three decades of primary health care: reviewing the past and defining the future. Bull world Health Organ. 2008;86:3.

2. Karkee R. Revitalising primary health care. Kathmandu Univ Med J. 2008;6(23):297.

3. Haines A, Horton R and Bhutta Z. Primary health care comes of age. Looking forward to the 30th anniversary of Alma-Ata: call for papers. Lancet. 2008;370:911-3.

4. Hall J, and Taylor R. Health for all beyond 2000: The demise of the Alma-Ata Declaration and primary health care in developing countries. Medical Journal of Australia. 2003;178(1):17-20.
5. Chan M. Return to Alma-Ata. Lancet. 2008;372:865-6.

6. WHO. World Health Report. Primary Health Care more than ever. Geneva: WHO; 2008.

7. Lawn JE, Rohde J, Rifkin S, et al. Alma-Ata 30 years on: revolutionary, relevant, and time to revitalise. Lancet. 2008;372:917-27.

8. Dixit H. Quest for Health Primary Health Care in Nepal. Kathmandu: Educational Enterprise (P) Ltd; 1994.

9. MoHP. National Health Policy. Kathmandu: GoN; 1991.

10. GoN/MoHP. Annual Health Report 2006-7. Kathmandu: Department of Health Services; 2007. 
11. GoN. Nepal Living Standard Survey 2003/04. Statistical Report volume One. Kathmandu: Central Bureau of Statistics, National Planning Commission Secretariat; 2004.

12. Chol PT. Human Resources for Primary Health Care in the South-East Asia Region: Categories and Job Descriptions. Regional Health Forum. 2006;10(1).

13. WHO/SEARO. Revitalising Primary Health Care-Country experiences/Nepal. In: Regional Conference on "Revitalising Primary Health Care";2008 Aug 6-8; Jakarta, Indonesia.

14. MoHP. Health Sector Strategy: An agenda for reform. In: Second Long Term Health Plan, 1997-2017. Kathmandu: GoN; 2004.

15. MoHP. Nepal Health Sector Program-Implementation Plan 2004-2009. Kathmandu: MoHP; 2004.

16. GoN/NPC. The Tenth Plan-PRSP. Kathmandu: GoN; 2003.

17. WHO/SEARO. Country Health System Profile-Thailand. [Online]. 2008 [Assessed 2008 Oct 22]. Available from: URL:http://www.searo.who.int/EN/Section313/Section152 5.htm

18. WHO/SEARO. Country Health System Profile-Nepal. [Online]. 2008 [Assessed 2008 Oct 22]. Available from: URL:http:// www.searo.who.int/EN/Section313/Section152 3.htm

19. WHO/SEARO. Country Health System Profile-Sri-Lanka. [Online]. 2008 [Assessed 2008 Oct 22]. Available from: URL:http://www.searo.who.int/EN/Section313/Section152 4.htm

20. Rhode J, Cousens S, Chopra M, et al. 30 years after Alma-Ata: has primary health care worked in countries? Lancet. 2008;372:950-61.

21. Ministry of Health and Population/New Era/Macro International. Nepal Demographic and Health Survey 2006. Kathmandu: $\mathrm{MoH}$; 2006.

22. UNDP. Human Development Report 2007-8: Country Fact Sheet. [Online]. 2008 [Assessed 2008 Oct 22]. Available from: URL:http://hdrstats.undp.org/countries/country_fact_shee ts/cty_fs_NPL.html

23. Taylor HG, Khadka R and Taylor CE. Health Equity in Nepal: A Half-Century of Health Development in the Kali Gandaki Valley, Western Region. USA: Johns Hopkins University, School of Hygiene and Public Health; 1999.

24. WHO/SEARO. Skilled Birth Attendants. WHO Country Office Nepal. [Online]. 2008 [Assessed 2008 Oct 22]. Available from: URL:www.nep.searo.who.int/LinkFiles/Home_ Skilled_Birth_Attendant1

25. WHO/SEARO. Strategic paper on Health Care Referral System in Nepal. WHO Country Office Nepal, 2007. [Online]. 2007 [Assessed 2008 Oct 22]. Available from: URL: www.nep.searo.who.int/LinkFiles/Home_Health_Care_Ref erral_System.pdf
26. Devkota SR. Socio-economic Development in Nepal: past mistakes and future possibilities. South Asia Economic Journal. 2007;8(2):285315.

27. Singh S. Impact of long-term political conflict on population health of Nepal. CMAJ. 2004 Dec 7;171(12):1499-501.

28. Aitken JM. . International Journal of Health Planning and Management. 1994 Oct-Dec;9:309-40.

29. Collins C, Omar M, Adhikari D et al. Health system decentralisation in Nepal: identifying the issues. J Health Organ Manag. 2007;21(6):535-45.

30. WHO/SEARO. Decentralisation of Health System and its management. WHO country office, Nepal. [Online]. 2008 [Assessed 2008 Oct 22]. Available from: URL:

31. Shakya G, Kishore S, Bird C, and Barak, J. Abortion law reform in Nepal: Women's right to life and health. Reprod Health Matters. 2004 Nov;12(24):75-84.

32. Nepal Safe Motherhood Project. Need Assessment Report Phase 2. [Online]. 2000 [Assessed 2008 Oct 22]. Available from: URL:http://www.nsmp.org/pdf/Needs-Assessments-ReportPhase2-Design+Planning---NSMP.pdf

33. Stone L. Primary health care for whom? Village perspectives from Nepal. Soc Sci Med. 1986;22(3):293-302.

34. Lafond AK. Improving the quality of investment in health: Lessons on sustainlability. Health Policy and Planning. 1995;10:63-7.

35. WHO. Health system in Nepal: Challenges and Strategic Options. Kathmandu: WHO country Office Nepal; 2007.

36. 36. Knoble SJ, Pandit A, Ghimire L et al. Measuring the quality of rural based government mid-level health care workers. Kathmandu: Nick Simon Institute; 2007.

37. Curtale F, Siwakoti B, Lagrosa C et al. Improving Skills and Utilisation of Community Health Volunteers in Nepal. Soc Sci Med. 1995;40(8):1117-25.

38. Purdey AF, Adhikari GB, Roninsion SA, and Cox PW. Participatory health development in rural Nepal: clarifying the process of community empowerment. Health Education Q. 1994;21(3):329-43.

39. Shrestha S. Increasing contraceptive acceptance through empowerment of femal community health volunteers in rural Nepal. J Health Popul Nutr. 2002 Jun;20(2):156-65.

40. Morrision J, Tamang S, Mesko $\mathrm{N}$ et al. Women's health groups to improve perinatal care in rural Nepal. BMC Preganancy and Childbirth. 2005;5:6.

41. Rostato M, Laverack G, Grabman LH, et al. Community participation: lessons for maternal, newborn, and child health. Lancet. 2008;372:962-71.

42. Walley J, Lawn JE, Tinker A, et al. Primary health care: maling Alma-Ata a reality. Lancet. 2008;372:1001-7. 